\title{
PROCEDURE FOR FORMING AND IMPLEMENTING THE STRATEGY OF ENTERPRISE DEVELOPMENT
}

\author{
Kateryna Malinoshevska ${ }^{1}$
}

\begin{abstract}
The purpose of the article shows that formulating a strategy is an important and necessary process because it helps to unite the efforts of many people and, through their coordinated work, achieve the set purposes: how to achieve the goals, what to do and how to direct the efforts of the company and its individual employees determines the strategy of the company. The problems that organizations face and how they can be solved are highly relevant in today's economy. Methodology. A scientific approach to solving problematic issues allows us to model possible situations and avoid negative consequences due to the wrong strategic policy of the organization. The main purpose of this article is to identify methodological approaches to the evaluation of the characteristics, properties of the enterprise development strategy and the introduction of classification strategies based on the performance indicators of enterprises that characterize the effectiveness of their functioning in the market. Results. Changing the environment in which an enterprise operates in a market economy forces the company to adapt to new conditions, that is, to formulate its strategy. Increasing the intensity of production, the maximum use of financial and labor resources, determine the need for new methods and approaches, that is, the strategy of enterprise development. In a competitive market, it is impossible to be successful by providing low-quality services or offering low-quality goods. Before developing business management processes, a functional strategy must be developed. Practical implications. Strategies at any level usually do not have resources or the ability to use resources in such a way as to ensure complete confidence in success. As a result, the final and important criterion is the risk assessment of less than the achievement of strategic goals. Acceptance of unavoidable risks is part of the work of strategists in the modern world, and the ability to clearly articulate the nature and extent of risk is the first step in reducing its impact. If the risk is defined as unacceptable, it is necessary to revise the tasks, changes in concepts, increase resources, or some complex of these actions. Improvement of the regulatory framework of strategic planning should include mechanisms, a number of regulatory documents and bills, the adoption of which will be carried out by the scientific and technological development of enterprises. The proposed specification of factors that influence the choice of strategy, the comparative characteristics of management systems, the proposed ways to increase the set of decision-making rules will help determine the main areas of activity of the enterprise.
\end{abstract}

Key words: company strategy, development strategy, strategy selection criteria, strategy implementation.

JEL Classification: F19, P20

\section{Introduction}

Having a clear and comprehensible strategy helps each business to be more efficient and profitable, while achieving the desired and expected results in advance. One of the main features of the strategy for today is the industrial environment, which influences technological evolution, economic trends, prices, exchange rates, volumes and more. When an enterprise needs to start a redevelopment action, it is necessary to find a compromise between short-term actions and long-term ones, i.e., an urgent strategy. The problems that often arise in the evolution of projects confirm the outdated approach to solving these problems. Conversely, continuous evolution management leads to rapid evolutionary action in an uncertain environment. Moreover, this approach naturally integrates industrial strategy, practices, concepts and methods to support enterprise evolution management. In the past, the evolution of the system and its efficiency have been extensive. Long-term and expensive projects have led to dramatic structural changes, and a production system has been implemented. This way of working leads to problems in the current

\footnotetext{
Corresponding author:

${ }^{1} \ll$ Highline Media» Ltd., Ukraine.

E-mail: katya.malinoshevska@inter.ua
} 
economic environment. Investing in such projects is a very important decision; you need to control the payback period of your investments.

Not all firms use officially adopted planning systems, and those that use do not always do this well. Formal planning provides a number of benefits: a systematic understanding of the situation, more precise coordination of the efforts of the company, more accurate statement of tasks and more advanced methods of measuring the achieved. All this should lead to an increase in sales and profits. The base for any other planning within the company is strategic planning. The strategic planning process consists of: developing a company program, formulating its goals and objectives, analyzing the business portfolio and long-term planning of the organization's growth. To ensure the growth of the company, strategic planning requires identifying market opportunities in areas where the company will have a competitive advantage. Such opportunities can be identified on the paths of intensive growth on the scale of current commodity-market activity, on the paths of integration growth within the industry and on the paths of diversification growth. Implementing a strategy is a critical process. In the case of successful implementation, it is this process that leads the enterprise to achieve its goals. The implementation of the strategy is carried out through the development of programs, budgets and procedures, which can be considered as mediumterm and short-term plans for the implementation of the strategy.

\section{Update of development of the enterprise strategy}

Strategy is an integrated model of action designed to achieve the goals of the enterprise. The content of a strategy is a set of decision-making rules that are used to identify the main areas of activity.

There are two opposing views on strategic planning in the understanding of strategic planning. In the first case, a strategy is a specific long-term plan for achieving a specific goal, and strategy development is the process of finding a specific goal and drawing up a long-term plan. This approach is based on the fact that all changes occurring are predictable, processes occurring in the environment are deterministic and subject to complete control and management.

In the second case, the strategy concerns the long-term, well-defined direction of development of the enterprise, in terms of the scope, means and form of its activity, the system of internal industrial relations, as well as the position of the enterprise in the environment. With this understanding, the strategy can be characterized as the chosen line of business, the functioning and framework of which should lead the organization to achieve its goals. In strategic planning, the direction of activity is usually chosen from the results of strategic analysis carried out using the BCG matrix and other matrices, as well as the results of the enterprise SWOT analysis (Hlushkova, 2013).

In business life, a strategy understands the general concept of how an organization's goals are achieved, its problems solved, and the limited resources required to achieve it. This concept (consistent with the second type of strategy) includes several elements. First of all, they are formed of a system of goals, including mission, corporate and specific goals. Another element of the strategy is policy, or a set of specific organizational action rules aimed at achieving the goals.

Typically, the strategy is developed several years in advance, specified in various types of projects, programs, practical actions and implemented in the process of their realization. The considerable labor and time costs of many people required to create an enterprise strategy do not allow it to be altered frequently or seriously adjusted. Therefore, it is formulated in fairly general terms. This is a conceived strategy.

At the same time, both inside and outside the organization, there are new contingencies that do not fit into the original concept of the strategy. For example, they may open up new prospects and opportunities to improve the current state of affairs or, conversely, force them to reject the proposed policy and action plan. In the latter case, the initial strategy becomes impracticable, and the company proceeds to consider and formulate urgent strategic objectives.

In general, an enterprise can develop and implement four main types of strategies:

1. Concentrated growth strategies are the strategies to strengthen market positions, market development strategy, product development strategy.

2. Integrated Growth Strategies are the Reverse Vertical Integration Strategy, Prospective Vertical Integration Strategy.

3. Diversification growth strategies are the centralized diversification strategy, horizontal diversification strategy. 
4. Reduction strategies are the elimination strategy, harvest strategy, reduction strategy, cost reduction strategy.

Any strategy incorporates general principles on the basis of which the organization's leaders can make interrelated decisions designed to achieve consistent and orderly achievement of goals in the long term. There are four different groups of such principles (rules):

1. The rules used in evaluating the results of the enterprise's activities in the present and in the future. The qualitative side of the evaluation criteria is usually referred to as the benchmark and the quantitative content is the task.

2. The rules by which the relationship of the company with its external environment, determining: what types of products and technology it will develop, where and to whom to sell its products, how to achieve an advantage over competitors. This set of rules is called a productmarket strategy or a business strategy.

3. Rules for establishing relationships and procedures within the organization. They are often referred to as an organizational concept.

4. The rules by which a company conducts its daily activities are called basic operating techniques.

The main features of the strategy identified by I. Ansoff in his book "Strategic Management", 1989:

1. The strategy development process does not end with any immediate action. Usually it ends with the establishment of general directions, the promotion of which will ensure the growth and strengthening of the company's position.

2. The formulated strategy should be used to develop strategic projects using the search method. The role of search strategy is, firstly, to help focus on specific sites and opportunities; Secondly, it is to give up all other options that are not compatible with the strategy.

3. The need for strategy disappears as soon as the real course of development leads the organization to the desired events.

4. During the formulation of the strategy it is impossible to foresee all the possibilities that will be opened in the development of specific measures. Therefore, we have to use highly generalized, incomplete and inaccurate information about the various alternatives.

5. As soon as specific alternatives are identified in the search process, more accurate information is displayed. However, this may call into question the validity of the initial strategic choice. Therefore, successful strategy implementation is not possible without feedback.

6. As both strategies and recommendations are used to select projects, it may seem that this is the same. But these are two different things. A benchmark is a goal the companystrives to achieve, and strategy is a means to an end. Landmarks are the highest level of decision making. A strategy justified by one set of benchmarks will not be the same if the organization's guidelines change.

7. Finally, strategy and benchmarks are interchangeable both at individual points and at different levels of the organization. Some business parameters (such as market share) can serve as a benchmark for a company at one time, and at other times it will be its strategy. Further, as guidance and strategies are developed within the organization, a typical hierarchy emerges: what is at the highest levels of strategy management elements at the lower levels is transformed into guidelines.

\section{Developing and implementing a strategy at the enterprise}

The company strategy is developed and implemented at all levels of strategic management:

The first level - corporate - is present in companies operating in several business areas. Here decisions are made on the acquisition, sale, liquidation, re-profiling of different business lines, strategic correspondence between different business areas is calculated, and diversification plans are developed, global finance management is provided by resources (Vovk, 2012).

The second level - business areas - is the level of the first leaders of non-diversified organizations or fully independent, responsible for the development and implementation of a business strategy. At this level, a strategy based on the corporate strategic plan is being developed and implemented, the main purpose of which is to increase the competitiveness of the organization and its competitive potential.

The third level - functional - is the level of heads of functional areas: finance, marketing, production, personnel management, etc.

The fourth level - linear - is the level of heads of organizational units or its geographically remote parts, such as representative offices, offices.

A non-diversified organization has three levels of strategies, respectively.

The variety of strategies used in strategic management makes their classification very difficult. Among the classification features, the most significant are: 
- level of decision making;

- the main concept of competitive advantage;

- industry life cycle stage;

- the relative strength of the industry position of the organization;

- the degree of "aggressiveness" of the organization's behavior in competition.

For example, the classification of enterprise strategies by decision level is as follows:

- corporate;

- business;

- functional;

- operational (the latter can be included in the functional).

A complicating factor in classifying strategies is that most strategies cannot be uniquely identified by one of the criteria. Zabelin P.V. and Moses N.K. there are three ways to classify strategies:

- ownership of five major competitive advantage strategies (global strategies);

- belonging to business portfolio management strategies (portfolio strategies);

- belonging to the strategies applied, depending on external and internal conditions (functional).

The strategy captures what decisions the enterprise must make in order to achieve the desired goals in the future, based on how the environment and the living conditions of the enterprise will change (Figure 1).

Choosing a strategy involves exploring alternative areas of the organization's development, evaluating them, and selecting the best strategic alternative for implementation. In this case, special tools are used, including quantitative forecasting methods, development of future development scenarios, and portfolio analysis (Nazarbaev, 1992).

We especially want to focus on the innovative nature of strategic decisions, forming a strategic space from proactive and active solutions. In the first case, we are talking about pre-emptive solutions that allow us to construct the dynamics of further changes in a profitable direction, to outperform all competitors in creating the conditions for necessary changes and to derive maximum benefit from the created conditions. This is the essence of proactive strategic decisions that have become most relevant nowadays, when strategies aimed at creating their own competencies, difficult to copy by other firms, are considered successful. Active strategic decisions are expressed in topical decisions on the generation of events and innovations that are significant

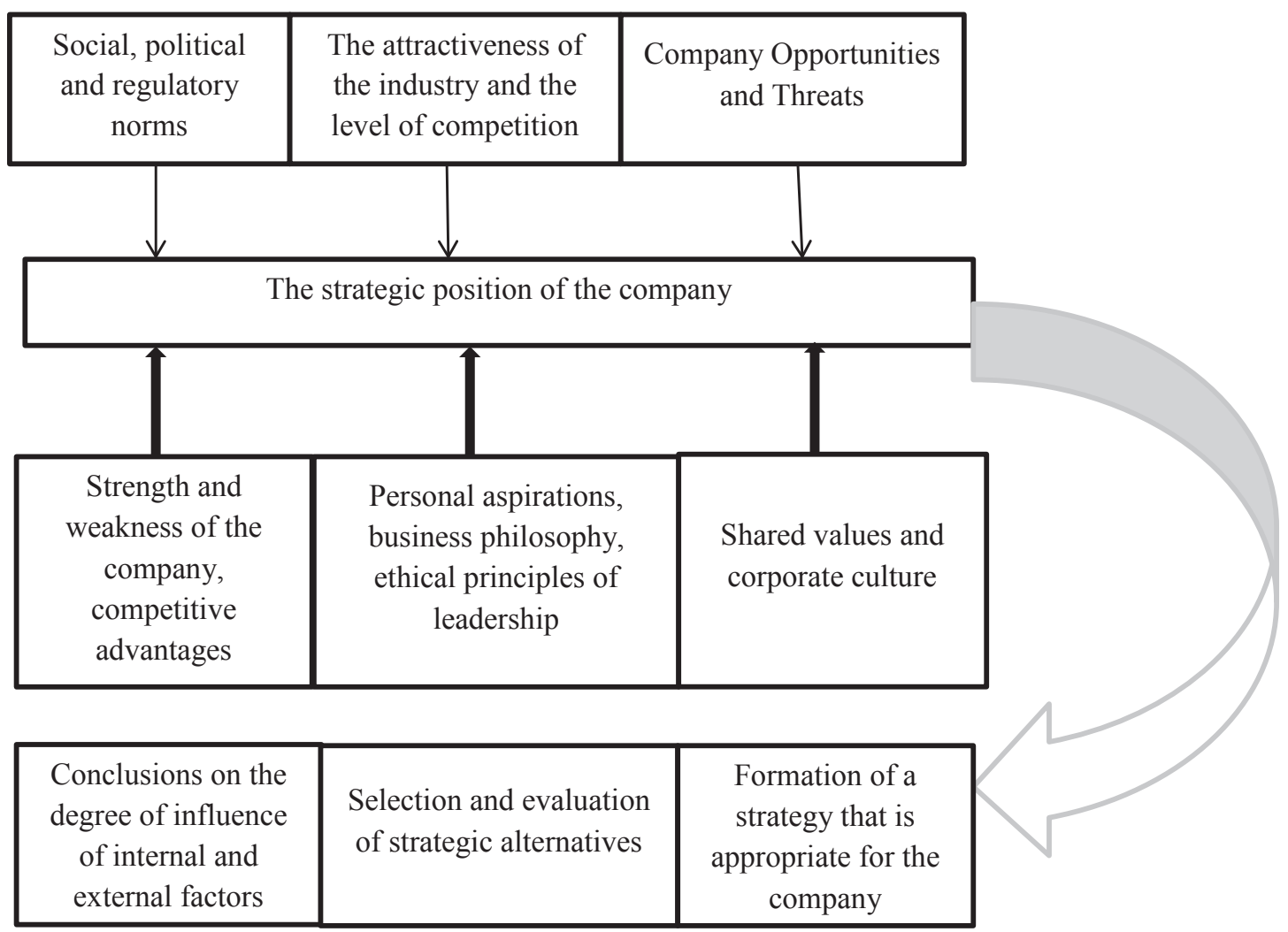

Figure 1. Factors influencing the choice of strategy 
for competitors, making the enterprise a leader of change, implementing innovative projects as impulses to the consumer and competitive communities (Mazaraki, Melnyk, Chaiun, 2000).

The strategy is implemented through the development of programs, budgets and procedures that can be considered as medium and short-term plans for strategy implementation.

In the process of implementing the strategy, each level of management solves its specific tasks and performs the functions assigned to it. Senior management is crucial. Its activities during the implementation phase of the strategy can be presented in five consecutive stages.

Stage One: In-depth study of the environment, goals and strategies developed. At this stage the following main tasks are solved:

- understanding the nature of the goals set by the strategy, their correctness and relevance to each other, as well as the state of the environment;

- bringing the ideas of the strategic plan and the goals to the employees of the enterprise in order to prepare the conditions for their involvement in the implementation of the strategies.

Second stage: development of a complex of solutions for efficient use of resources available to the enterprise. At this stage, resources are assessed, allocated and aligned with the strategies implemented. For this purpose, special programs are being prepared, the implementation of which should promote the development of resources. For example, these could be employee development programs (Project Jacquard, 2018).

In the third stage, senior management decides to make changes to the existing organizational structure.
The fourth stage is to make the necessary changes in the enterprise, without which it is impossible to start implementing the strategy. For this purpose, a scenario of possible resistance to change is developed, and measures are taken to eliminate or minimize real resistance and to consolidate change.

Stage Five: Update your strategic plan if new circumstances urgently require it.

Therefore, difficult situations require the ability to anticipate the possible development of processes, events and the state of future probable situations. Thus, any significant and large-scale events objectively require a strategic approach to management (Strategies of Foreign Markets Entry, 2018).

The results of the implementation of the strategy are evaluated and through the feedback system the organization is monitored, during which the previous steps can be adjusted (Table 1).

The introduction of long-term planning has given rise to an approach to strategy as a set of goals, which is understood as a set of long-term goals and objectives that ensure the effective interaction of the enterprise with the external environment. But any goal forms a decision space in which a company must make only one, the most optimal choice from the point of view of its own development.

\section{Conclusions}

In the era of comprehensive planning, strategy is increasingly perceived as a detailed, comprehensive plan designed to help achieve the mission and goals of the organization. The strategic plan, from our point of view, describes the main stages of achieving the long-term goals, but does not determine the

Table 1

Comparative characteristics of control systems

\begin{tabular}{|c|c|c|c|c|}
\hline Parameters & $\begin{array}{l}\text { Control Based } \\
\text { Management }\end{array}$ & Extrapolation Control & $\begin{array}{c}\text { Change-Based } \\
\text { Management }\end{array}$ & Strategic management \\
\hline Assumptions & The past repeats itself & Trends persist & $\begin{array}{l}\text { New developments / } \\
\text { trends are predictable }\end{array}$ & $\begin{array}{l}\text { Partial Predictability } \\
\text { for Weak Signals }\end{array}$ \\
\hline Type of change & Slower Firm Response & $\begin{array}{l}\text { Compare with the } \\
\text { reaction of the } \\
\text { company }\end{array}$ & $\begin{array}{l}\text { Faster company } \\
\text { response }\end{array}$ & \\
\hline Process & \multicolumn{2}{|c|}{ Cyclical } & \multicolumn{2}{|c|}{ Real time } \\
\hline Management basis & $\begin{array}{c}\text { Deviation control, } \\
\text { integrated management }\end{array}$ & Target management & Strategic analysis & $\begin{array}{l}\text { Accounting for market } \\
\text { development and the } \\
\text { environment }\end{array}$ \\
\hline $\begin{array}{l}\text { Emphasis in } \\
\text { management }\end{array}$ & Stability / reactivity & Foresight & Research & Creation \\
\hline Period & Since 1900 & Since the 1950 s & Since the 1960 s & Since the 1980s \\
\hline
\end{tabular}


optimal path of the enterprise in the space of decisions.

When recurring planning becomes an enterprise management practice, managers perceive the strategy as a behavior line. This interpretation is linked to a real understanding of strategy. Moreover, strategy as a plan and strategy as a line of conduct are level: the organization develops plans for the future and draws on principles of behavior from its past.
The strategy captures what decisions an enterprise must make today to achieve its desired goals in the future, based on how the environment and living conditions of the enterprise will change. The strategy of the enterprise should be based on determining the optimal path of development, on the vision of the future, on a qualitatively new state, on creation of favorable conditions for the enterprise and consist in making active and active innovative decisions aimed at creating difficult competencies.

\section{References:}

Hlushkova, T. V. Innovation components of the modern advertisement. Available at: http://nbuv.gov.ua/ UJRN/apmk_2013_14_31 (accessed February 25, 2020).

Video Mapping. Available at: https://ru.wikipedia.org/wiki/Видеомаппинг (accessed March 03, 2020). Vovk, I. P. (2012). Osoblyvosti vprovadzhennia zakhodiv resursozberezhennia ta metodyka vyznachennia yikh efektyvnosti na mashynobudivnykh pidpryiemstvakh $\mathrm{v}$ konteksti resursonomiky [Features of resource conservation measures and methods of their effectiveness in engineering enterprises in the context of resourcenomy]. Visnyk of Sumy State University. Economics Series, no. 4, pp. 107-117.

Project Jacquard. Available at: https://atap.google.com/jacquard/ (accessed March 07, 2020).

Nazarbaev, N. A. (1992). Strategiia resursosberezheniia i perehod k rynku [The resource-saving strategy and transition to the market]. Moscow: Mashinostroenie. (in Russian)

Official Website of the Analytical Agency Business Views. Available at: http://businessviews.com.ua/ (accessed February 15, 2020).

Mazaraki, A. A., Melnyk, T. M., \& Chaiun, T. I. (2000). International marketing: textbook for students of HEI. Kyiv: KNTEU, 306 p.

Strategies of foreign markets entry: expand business rightly. Available at: http://powerbranding.ru/ marketing-strategy/market-entry/ (accessed February 28, 2020). 